\section{A NEW MODE OF CONSTRUCTING CANNON}

BY J. C. BABCOCK, C. E., CHICAGo, ILL.

Notwithstanding the very satisfactory accomplishments of modern artillery, there yet remains a great opportunity for improvement in its efficiency. This branch of military science should receive a greater shure of the attention of our scientific men, for if cannon are to be constructed doubly efficient to any now in use, we cannot, without imminent danger, shut our eyes to the fact.

Better fielu pieces are wanted, combining greater strungth and lightness. Before any degree of perfection in both these requirements can be obtained, the following problem must be solved:--What method of construction will occasion the most equal distribution of the circumferential strain, throughout the mass of metal?

No known material is capable of receiving a tensile strain without stretching. Cannon are subjected to two indirect tensile strains, circumferential and longitudinal. Now it has long been known (but not generally understood) that increasing the thickness of metal in a gun does not increase its circumferential strength beyond a certain point. This fact is easily proved and explained by the following experiment:If we make equi-distant concentric lines on the end of a hollow cylinder of soft brass, Fig. 1, and impart an equal circumferential strain by means of a circular wedge driven into the bore, Fig. 2 , we can at once observe how much more the inside is stretched than the outside, or even the intermediate spaces. The spaces between the lines will be seen to vary in width in lirect proportion to the amount of strain on each, showing that while the inside space is strained almost to breaking, the intermediate spaces are much less strained, and the outer scarcely any at all.
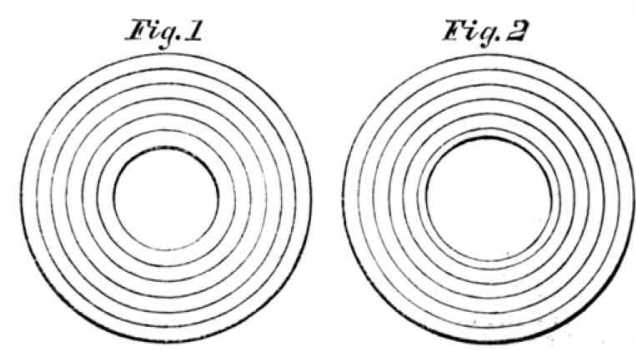

Now if we increase the strain sufficiently to produce fracture, by driving the wedge still deeper, Fis. 3 , it will be observed that the inner spaces will be completsly severed, while the outer remains comparatively sound.

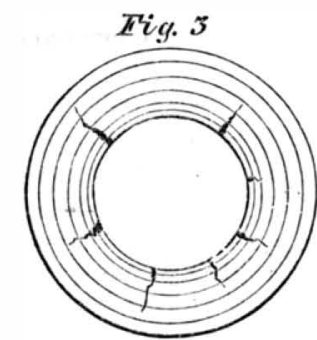

The law has been found that in cylinders of metal the circumferential strain on the different parts varies inversely as the squares of the distances of the parts from the axis. According to this ratio a two-inch gun with two inches of metal, will be internally fractured before the exterior receives one-twelfth part of the strain causing the fracture. Of course increas ing the thickness still more would add very little to its strength.

The longitudinal strength has a direct bearing on the circumferential. The metal undergoing the opposite strains of compression and extension at the same time, is weakened in the former capacity in proportion to the strain in the latter, therefore increasing the longitudinal strength by adding thickness to the gun, increases its circumferential strength, but is only to a certain degree.

Longitudinal strain being uniform does not affect our ratio of the circumferential strain. Ordinary guns have a longitudinal strength twelve times greater than their circumferential, while the strain in the latter direction is eight times as great as in the former.

I think no better disposition of a solid mass of and breech-loading. metal will ever be made than in the scientific pro portions of the Dahlgren guns; yet what a pity to have so much of the material comparatively idle.

How then are we to cqualize this immense circumerential strain which possesses the same ratio of inequality in all solid masses of metal?

A scientific arrangement of the material should be made whereby the several parts would take a moderate share of the strain, instead of the interior parts having too much and the exterior too little.

Numerous plans have been tried to accomplish the object, yet none have succeeded better than Armtrong or Whitworth. The wonderful accuracy and range of their guns is owing to the great velocity given to the shot which their method of construction alone renders possible. Their respective plans, although alike in principle, differ somewhat in execution. Their guns are built with concentric tubes or ings shrunk successively on each other with a gradual tension. The tension is increased from the interor to the exterior of the gun by a greater expansion in the heating of the different parts.

Another plan has been attempted to accomplish the same object by winding wire around a cylinder ncreasing the tension each layer. Were there no ongitudinal strain to contend against this plan would approach perfection; but it being necessary to raze the wire together in order to give the gun sufficient longitudinal strength, the heat required in the peration destroys the tension, rendering the gun at nce inferior to one wrought in a solid mass.

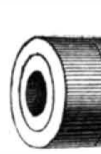

$$
\text { Fig. } 4
$$

As has been said before, the longitudinal strain weakens the circumferential strength; this is a fact pertaining to all cannon that have yet been constructed. The idea has occurred to me, that in such a predominance of the longitudinal strength compared with the strain, that such an arrangement of materia might be made whereby the longitudinal strain would assist, instead of weakening the circumferential strength. My plan for accomplishing so seeming an impossibility is as follows :

On a cylinder of cast iron (the best material for th inside of a cannon) shrink a layer of wrought.iron rings with moderate tension; these, with the cylinder should form about one-half of the thickness of the gun, Fig. 4. Bands of steel should now be wound spirally in alternate layers to the required thickness, reversing the winding each layer, Fig. 5. These bands should be wound while heated directly from furnace prepared for the purpose, and the tension increased on each layer in proportion to its distance from the bore, by regulating the heat.

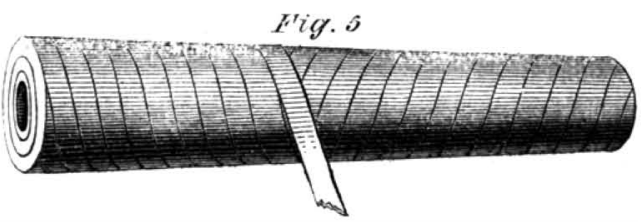

I am inclined to believe that this method of construction will make a stronger gun than has yet been produced. The longitudinal strain on the spiral windings, increases the tension at the moment of discharge when and where it is most needed, for no spiral can be extended longitudinally without diminish ing in diameter. The arrangement of the materials in the order of their expansive properties, gives mor work to the exterior of the gun, for cast iron is doubly more expansive than wrought iron, and wrought iron even doubly more expansive than steel.

The proper proportionment of the different materials in such a construction can only be obtained by experiment; when found, a gun must be made of immense strength and comparatively light.

An increase of strength in a cannon is an increase of its power and efficiency as an engine of war, especially when lightness is also combined. Modern ingenuity is advancing the perfection of the powder, bore and projectiles far more rapidly than the gun itself will permit of, and when cannon are made stronger and more scientifically, it will be time to turn our attention to the minor considerations of projectiles
An Article Resembling Honey.

A patent has lately been taken out by Charles Stevens, of London, for manufacturing a peculiar article for domestic use, which is stated to resemble honey, and is described as follows in Newton's Journal of Arts : To two hundred and filty parts of water, a hundred parts of the fecula of potato (or fecula procured from other prouted and malted barley diastase, to the aivalent in -2000 of the above quantity of fecula, is well mixed. The composition is then exposed to heat, which is gradually increased from $70^{\circ}$ to $75^{\circ}$ Reaumur,to obtain saccharIation. In orler to act with greater celerity, and alsowith more precision as to the saccharization, instead of having but one operation, as above described, the mixture is divided into two equal parts, each of which undergoes heating, the other. The two are then united, and the whole is sub. jected to evaporation till it has acquired the consistency of honey, and is bleached by animal charcoal, albumine, or other similar and suitable means.

Thick sirup of fecula obtained by acids, perfectly neutralized, may be substituted for the first liquid, in which, while boiling, a small quantity of polenta of potatoes is
mixed. This is kept stirred till cool, and to it is added 3-20 of the entire quantity of honey or honey-comb and 3-20 of the entire quantity of honey or honey-comb, and

\section{Mospger \\ THe}

SCIENTIFIC AMERICAN. THE BEST MECHANICAL PAPER IN THE WORLD SEVENTEENTH YEAR. VOLUME $\overline{\nabla .-\mathrm{NEW}}$ SERIES.

$\Lambda$ new volune of this widely circulated paper commenced on the 6th of July. Every number contains sixteen pages of useful in formation, and from five to ten original engravings of new inventio Tiscoveries, all of which are prepared expressly for its columns.
The SCIENTIFIC ANIERICA N is devoted to the interests of Popula Science, the Mechanic Arts, Manufactures, Inventions, Agricnlture Commerce and the Industrial Pursuits generally, and is valuable and instructive nut only in the Workshop and Manufactory, but also in the Household, the Library and ths Reading Eoom.

The SCIENTIFIC AMERICAN has the reputation, at home and abroad, of being the best weekly publication devoted to mechanical and industrial pursuits now published, and the publishers are determined to keep up the reputation they have earned during the SIXTERN TEARB they have been connected with its pubiication.

To the Inventor!

The SCIENTIFIC AMERICAN is indispensable to everg inventor, as it not only contains fllustrated descriptions of nearly all the best inventions as they come out, but each number contains an Offcial List of the
Claims of all the Patentsissued from the United States Patent Oflice during the week previous; thus giving a correct history of the progress of inventions in this country. We are also recelving, every week the best scientific journals of Great Britain, France, and Germany ; thus placing in our possession all that is transpiring in mechanical science
and art in these old countries. We shall continue to transfer to our columns copiousextracts from these journals of whatever we may deem
cour of interest to our readers.

To the Mechanic and Manufacturer!

No person engaged in any of the mechanical pursuits should think "doing without" the ScikNTIFIC AMERICAN. It costs but four cents per "celk; every number contalns from six to len engravings of new ma chines and inventions, which cannot be found in any other publicatio It is an established rule of the publishers to insert none but original en gravings, and those or the first-class in the art, drawn and engraved by

Chemists. Architects, Millwrights and Farmers! The SCIENTIFIC ANERICAN will be found a most useful journa to them. All the new discoreries in the science of chemistry are given in its columns, and the interesls of the architect and carpenter are no overlooked; al: the new inventions and discoveries appertaining to cal pursuits being published from week to week. Useful and practlowners will be found published in the SciEstiric AMrights and mill. owners will be found published in the SCIENTIFIC AMERICAN which in formation they cannot possibly obtain from any other source. Subject in which planters and farmers are interested will be found discussed implements being illustrated in its columns. TERMS

To mail subscribers:-Two Dollars a Year, or One Dollar for six months. One Dollar pays for one complete volume of 416 pages ; two

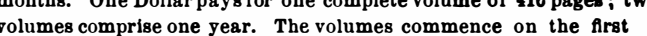
JANUARY and JULY. CLUB RATES.
J

Five Coples, for Six Months.

Ten Copies, for Six Months.

Ten Coples, for Twelve Months

Fifteen Copies, for Twelve Months.

or all clubs of Twent Twelve Months....................898 Names can be sent in at different times and from different Post-ofices Specimen copies will be sent gratis to any part of the country.

Western and Canadian money or P(st-offce stamps taken at par for subscriptions. Canadian subscribers will please to remit 25 cent 2 extra on each year's subscription to pre-pay postage. 